\title{
EHMTI-0253, syncopal migraine: factors that influence the positive response to tilt table testing
}

\author{
G Corcea*, S Odobescu, O Grosu, C Chicu-Hadarca, D Concescu, I Moldovanu, L Rotaru \\ From 4th European Headache and Migraine Trust International Congress: EHMTIC 2014 \\ Copenhagen, Denmark. 18-21 September 2014
}

\section{Background}

Syncopal migraine is a condition when patient has migraine and syncope simultaneously (Curfman, 2012). Both conditions are known to present with autonomic imbalance that may determine a positive response to tilt table testing.

\section{Aim}

Was to evaluate the factors that could influence the tilt table response in syncopal migraine.

\section{Method}

The study sample consisted of 65 patients with syncopal migraine. All the patients underwent detailed clinical examination and tilt table testing using Westminster protocol. According to the response on tilt test, the patients were divided in two groups and compared: $\mathrm{Gr}$. I $(\mathrm{N}=32)$ with positive response and Gr. II $(\mathrm{N}=33)$ with negative response. All the data collected were analyzed using SPSS software.

\section{Results}

In the syncopal migraine sample, $50.7 \%$ of the patients had positive response to the test (developing presyncopal or syncopal symptomatology during the test). The first group presented increased frequency of headache-days per month (9.18 vs. 3.13, $\mathrm{p}<0.001)$, more severe headaches (8.1 vs. 6.7, VAS, $\mathrm{p}<0.05)$, more expressed anxiety and depression, according to Spilberger test ( $36.5 \pm 1.7$ vs. $29.26 \pm 1.7$, $\mathrm{p}<0.05)$ and depression Beck score $(8.03 \pm 0.09$ vs. $5.01 \pm 0.6$, $\mathrm{p}<0.05)$, respectively. The Nijmegen score was very high in the group I ( $31.56 \pm 1.4$ vs. $15.29 \pm 1.0, \mathrm{p}<0.001)$ indicating the presence of a respiratory dysfunctional syndrome.

\section{Conclusion}

Frequent and severe headaches, increased anxiety and depression, the presence of dysfunctional respiratory syndrome could be the factors that predispose syncopal migraine patients to positive response on tilt table testing, which is an orthostatic stress and indicate autonomic imbalance and increased cardiovascular reactivity.

No conflict of interest.

Published: 18 September 2014

\section{doi:10.1186/1129-2377-15-S1-E31}

Cite this article as: Corcea et al.: EHMTI-0253, syncopal migraine: factors that influence the positive response to tilt table testing. The Journal of Headache and Pain 2014 15(Suppl 1):E31.
Submit your manuscript to a SpringerOpen ${ }^{\odot}$ journal and benefit from:

- Convenient online submission

- Rigorous peer review

- Immediate publication on acceptance

- Open access: articles freely available online

- High visibility within the field

- Retaining the copyright to your article 